\section{Wall House}

\section{Lampa, Chile}

El control climático y lumínico es tomado como generatriz de una vivienda ubicada en la zona central de Chile. A través de la creación de capas sucesivas desde el interior, se conforman los espacios privados y comunes, en un contexto velado por los mantos exteriores que controlan la luz y las vistas.

Marc Frohn Profesor, Royal College of Art

Mario Rojas Profesor, Universidad Andrés Bello

Cristóbal Palma, Archivo FAR Frohn \& Rojas Architects
The climatic and lighting control is treated as the design-generator of a home located in the central zone of Chile. Through the creation of successive layers from the interior, the private and common spaces are shaped in relation with the context veiled by exterior cloaks that control light and views.

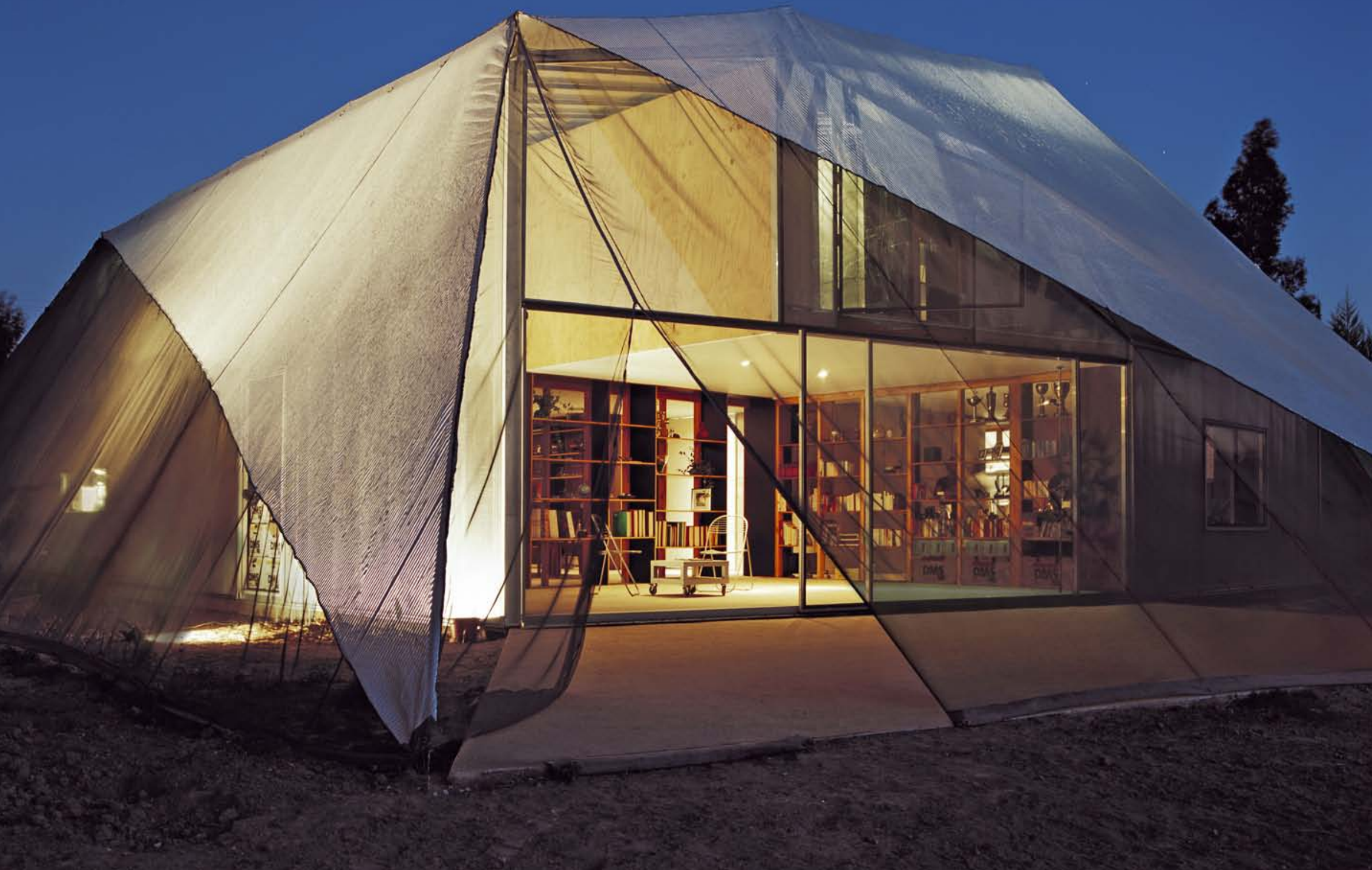




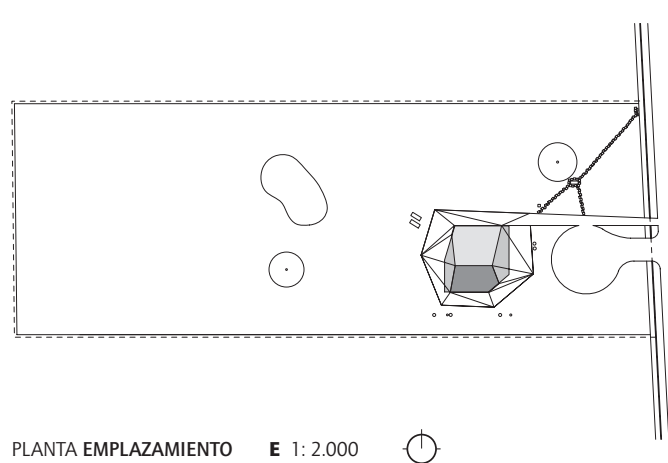

Contratados para diseñar una casa unifamiliar para un matrimonio en Santiago de Chile -con un muy reducido margen económico-la oficina se vio inmediatamente atraida por el doble carácter del terreno, que se encuentra en un suburbio a lo largo de la carretera Panamericana Norte. Mirado en forma precisa, el terreno es parte del Santiago suburbano y, al mismo tiempo, de un circuito de caminos rurales, con terrenos de más de $5.000 \mathrm{~m}^{2}$, altos arbustos que lo rodean y un carácter de aislamiento, ruralismo, tranquilidad y reposo. Estos setos vivos le dan a las parcelas mucha privacidad y aislamiento, mientras muestran la silueta de la cordillera de Los Andes en todo su esplendor, hacen desaparecer casi por completo y gradualmente los contornos inmediatos. Sobre esta base se consideraron los setos como las paredes exteriores de la casa, con lo cual el terreno completo forma parte de la vivienda. Se desarrolló desde ese punto de vista, el concepto de una casa compuesta de una serie de layers o capas separadas, que se van disolviendo desde el interior al exterior, partiendo de un núcleo masivo hasta una suave malla climática.

Mientras que las casas unifamiliares tradicionales se ayudan de muros, ventanas y puertas claramente definidas para separar lo interno de lo externo, en este proyecto se difumina la transición entre ambos y se integra con ello el terreno a la casa. Cada una de las cuatro layers, entre las cuales se forman una serie de espacios, se caracteriza por las propiedades climáticas, atmosféricas, estructurales, materiales y funcionales que le son propias y contribuyen, de esta manera, a una jerarquía inteligente para este económico proyecto. Al tiempo que las zonas interiores albergan las funciones más exigentes -cocina y baños-, la casa embrutece por la selección de los materiales y superficies hacia el exterior. Los movimientos de espacio a espacio dentro de la vivienda consiguen siempre la sensación de traspasos hacia adentro o afuera. Esta sensación es incrementada además por el cambio de materiales e iluminación.
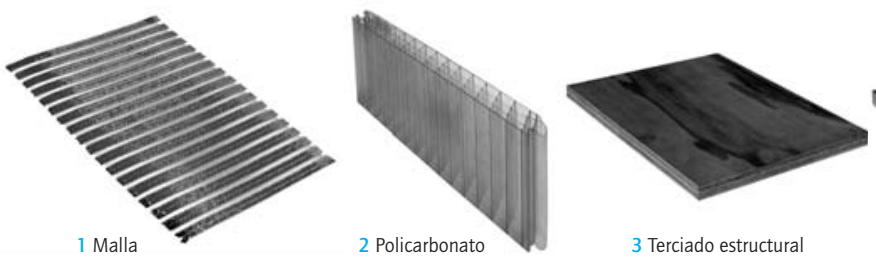

3 Terciado estructural
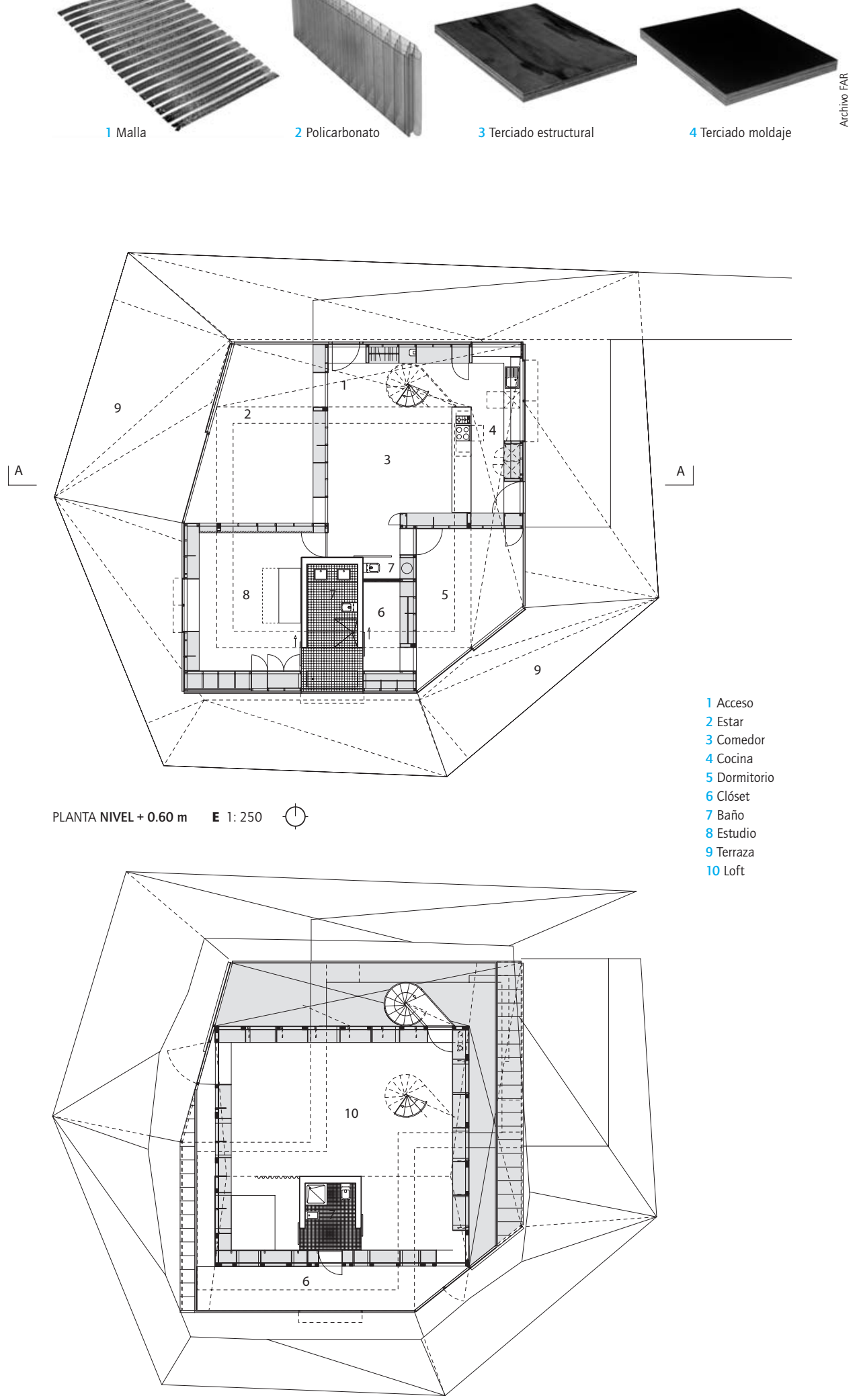

PLANTA NIVEL + $3.32 \mathrm{~m}$

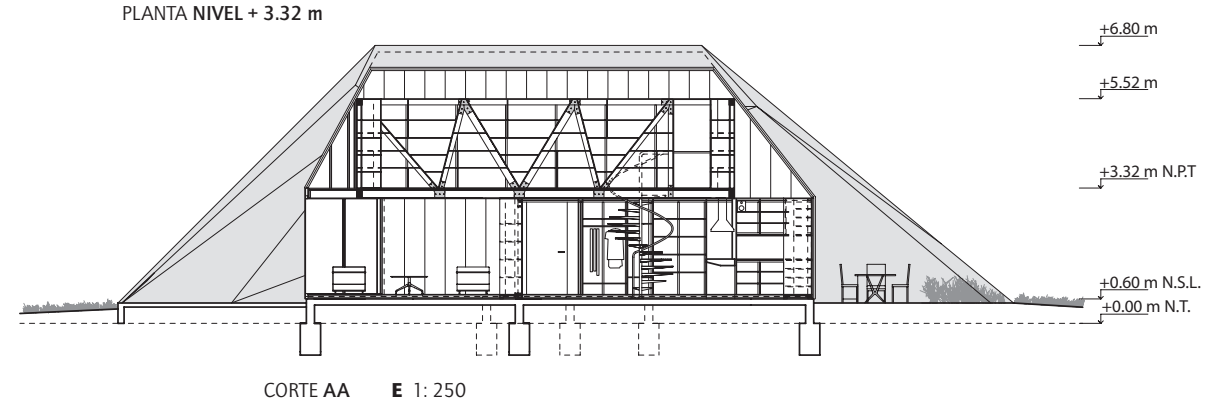



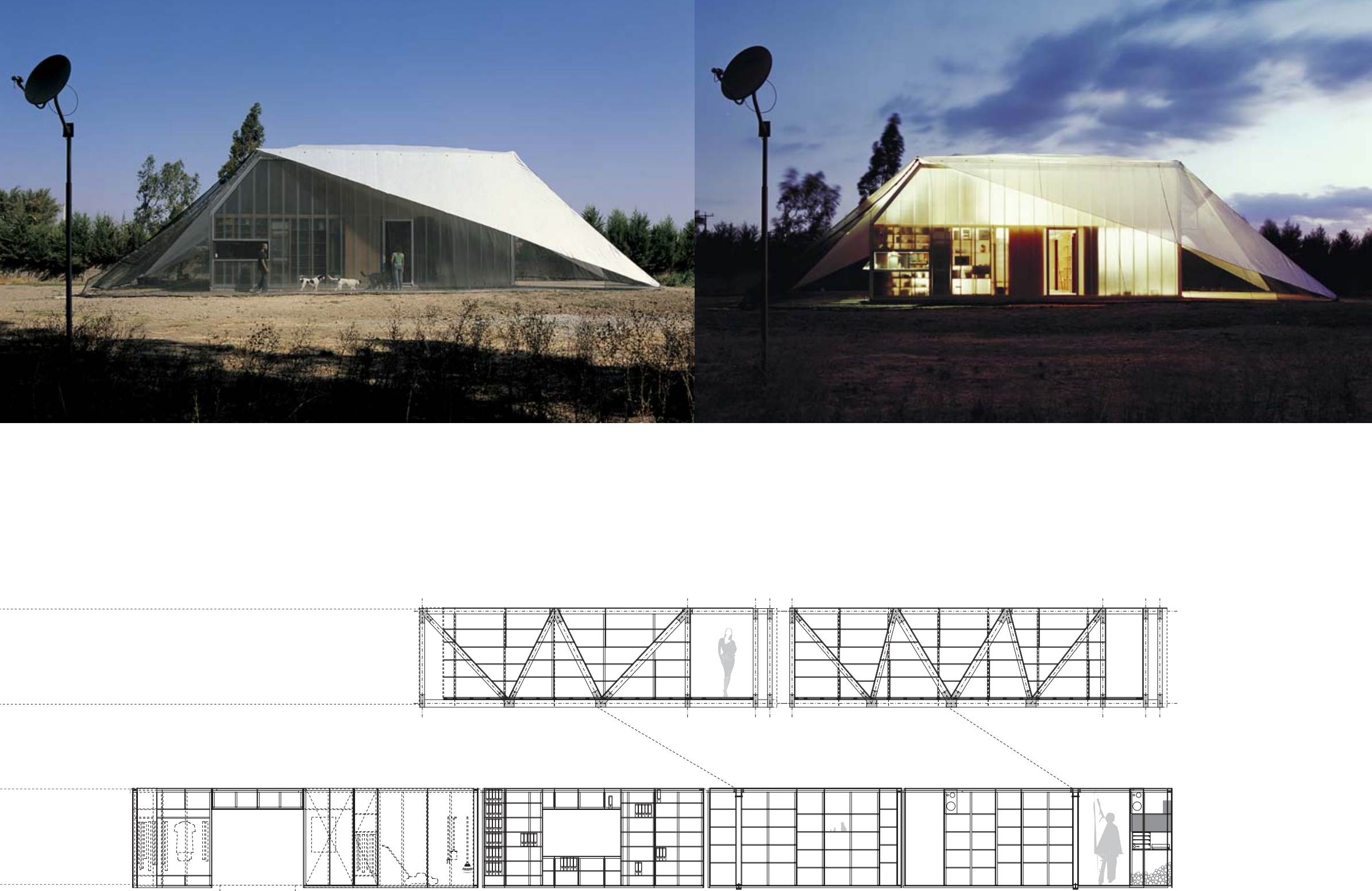

DESPLIEGUE B Staked Shelving E 1:100

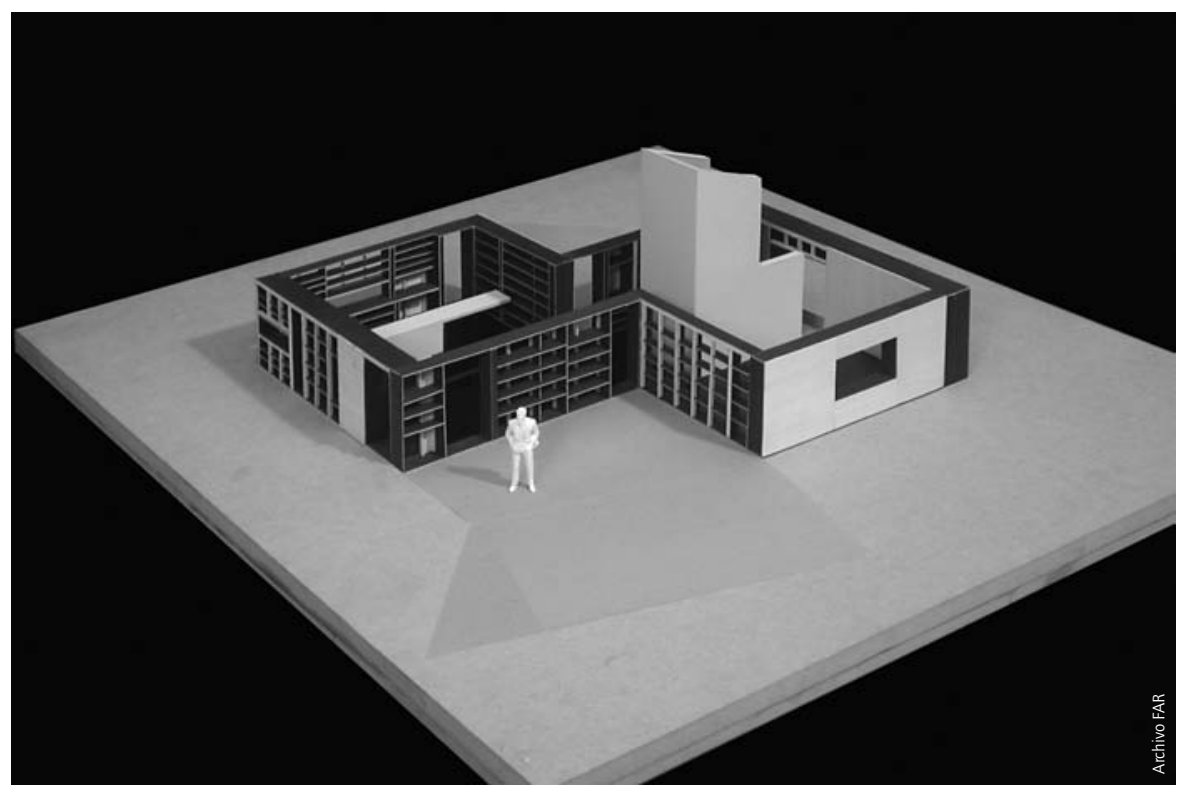

LAYER 2: STACKED SHELVING / El núcleo está rodeado de dos cintas de repisas, una sobre otra, que conforman el soporte de la casa y que están compuestas de madera laminada, moldajes y terciados. Ya que están desplazadas en su posición -respecto a otra- sus esquinas aparecen como voladizos de hasta 5,20 m. Mientras el dorso de las cintas se cierra con terciado en algunas partes, en otras, quedan completamente abiertas, con lo cual no solo consiguen espacio para guardar menaje, sino que también permiten a los propietarios la exposición de artículos personales y el ingreso de luz natural. La utilización de moldajes y terciados fue una decisión intencionada, que refleja el financiamiento moderado del proyecto.

Una relación de espacios secuenciales es definida por las cintas: en la cocina, comedor y dormitorio de huéspedes, en la planta baja, y en el loft de trabajo en el piso superior. 

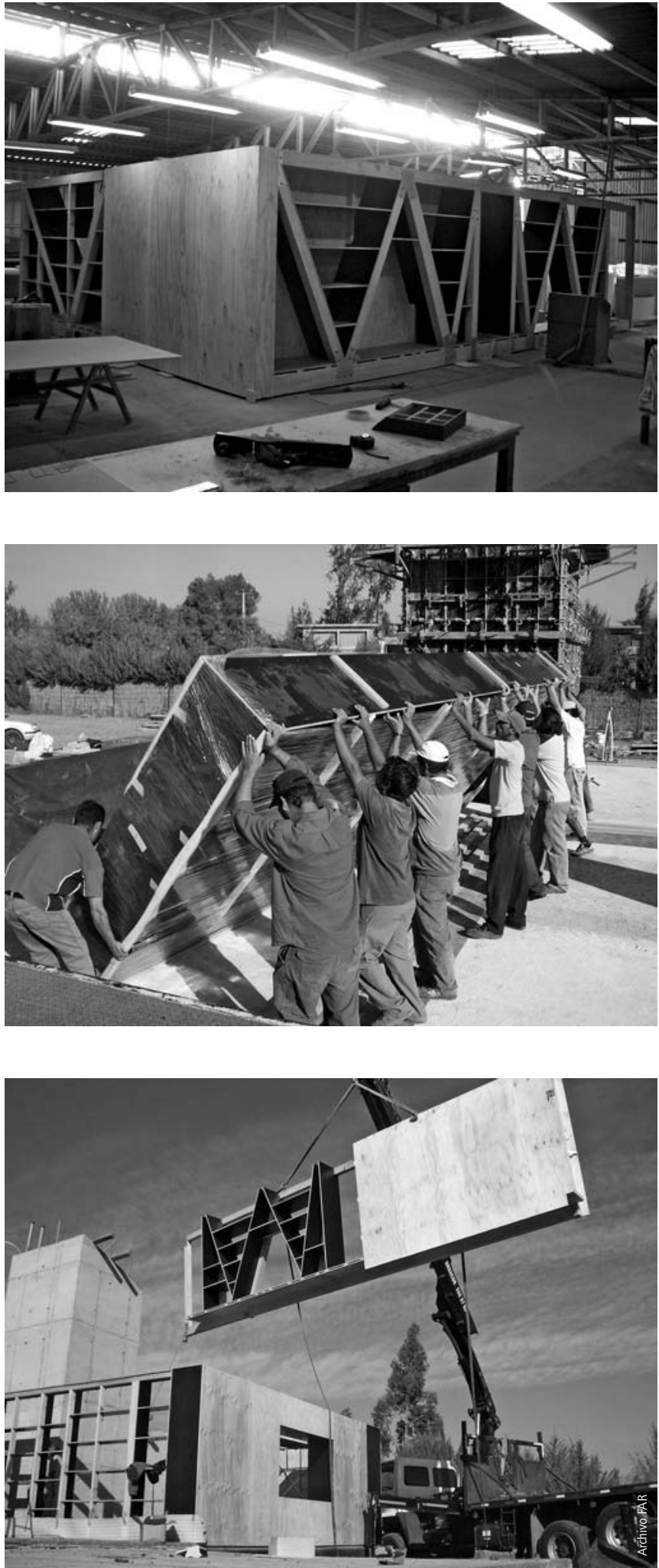
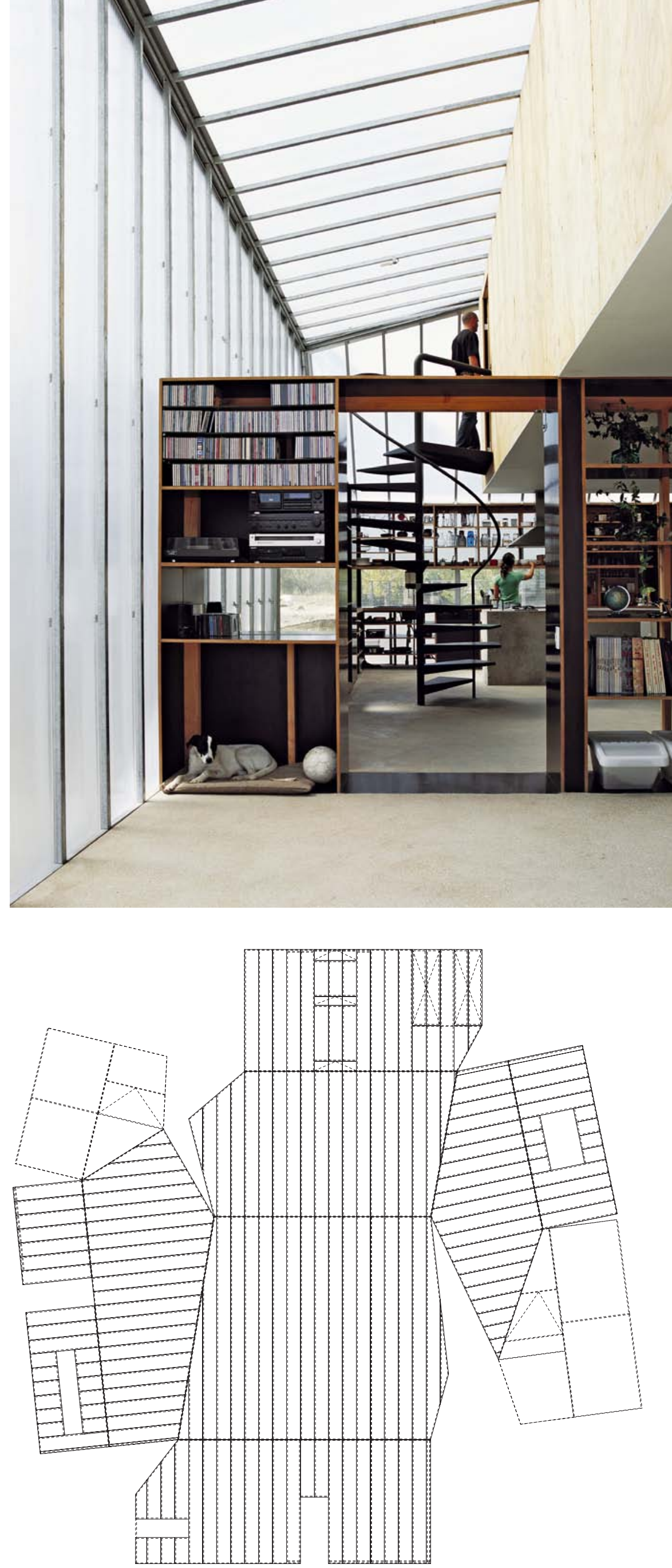

DESPLEGUE Milky Shell E 1:200 


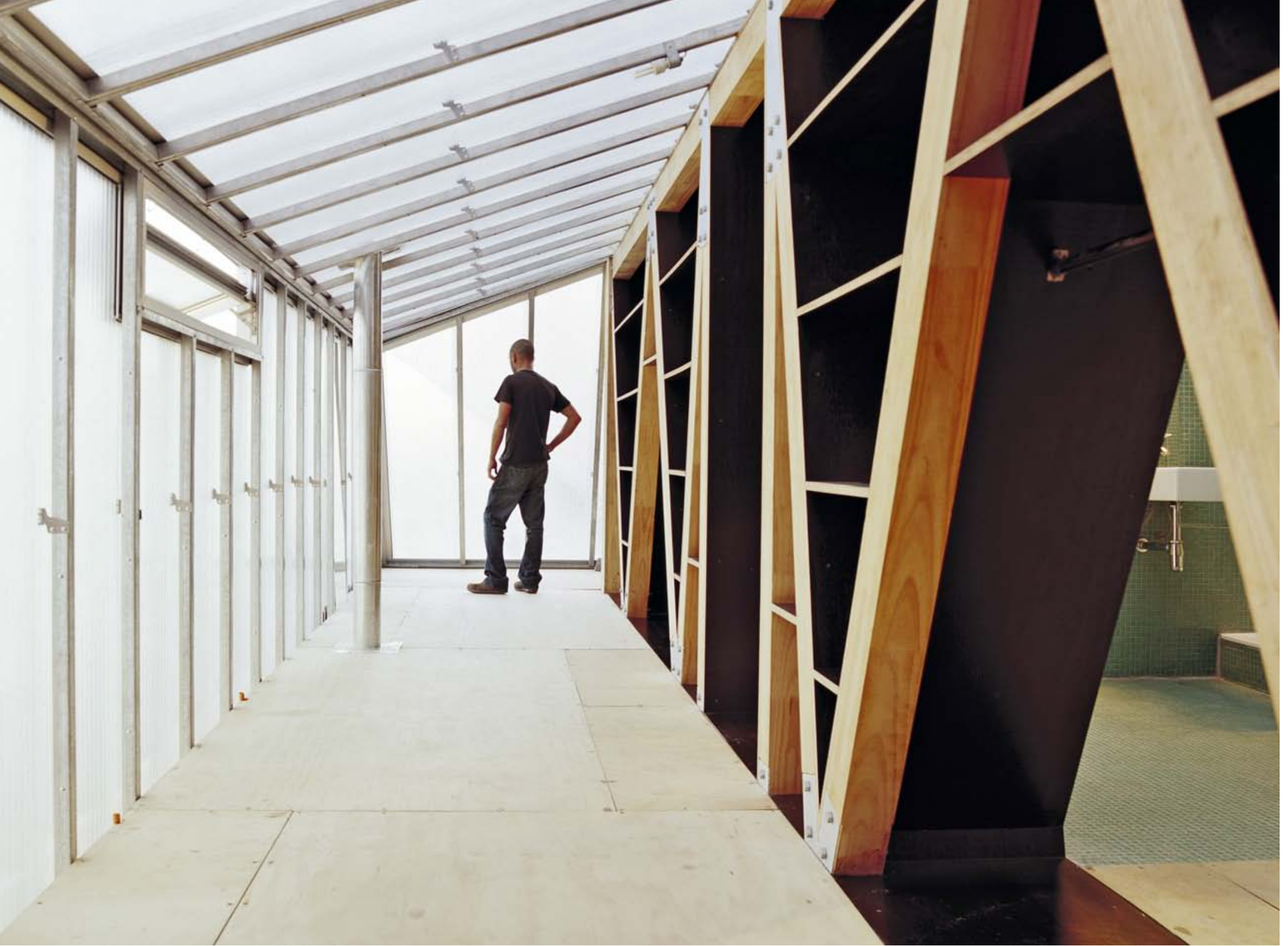

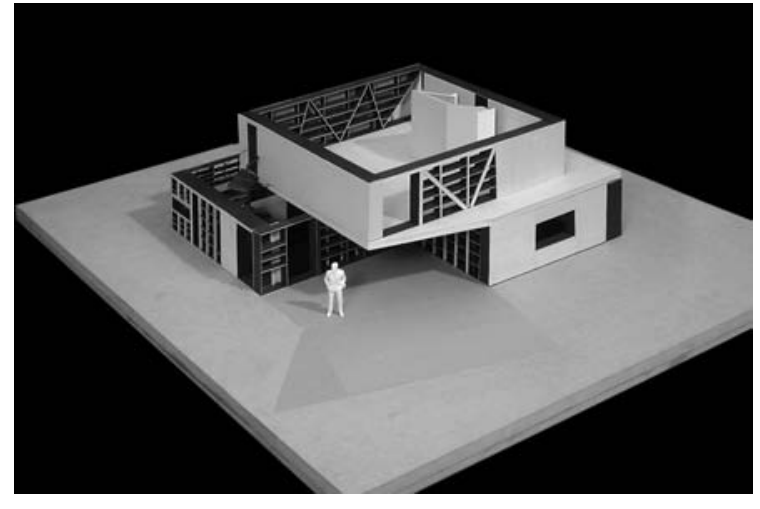

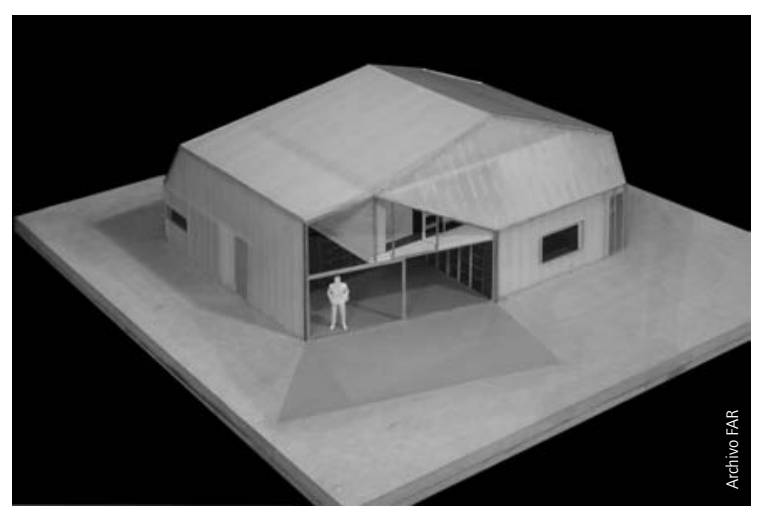

LAYER 3: MILKY SHELL / Alrededor de las repisas exteriores se despliega la piel climática de la casa. Esta se compone de paneles de policarbonato translúcido multicelular, en cuya superficie se vislumbran las sombras de los árboles y los alrededores, a la vez que los espacios entre cintas se iluminan con luz natural. En dos partes de la capa climática se reemplaza el policarbonato por termopaneles de vidrio transparente. Como soporte de los paneles de policarbonato, el proyecto utiliza simples perfiles galvanizados que se usan normalmente en la construcción de tabiquerías livianas o drywall. Estos se montan verticalmente sobre la construcción base y siguen la dirección de los paneles, suplantan las costaneras y aumentan con el aspecto superficial de la capa de policarbonato. Este material se extiende como un embalaje al vacío sobre los bordes de las cintas que se encuentran debajo y da forma a dos espacios de doble altura. Entre la cinta y esta capa, se constituyen la sala de estar y el dormitorio principal como piezas hacia el exterior que, al mismo tiempo, se ven iluminadas con luz natural. Grandes puertas corredizas aumentan estos espacios sobre las terrazas. 
